\title{
Perspectives on the Intracellular Bacterium Chlamydia pneumoniae in Late-Onset Dementia
}

\author{
Brian J. Balin ${ }^{1}$. Alan P. Hudson ${ }^{2}$ \\ Published online: 10 July 2020 \\ (C) The Author(s) 2020
}

\begin{abstract}
Purpose of Review Chronic diseases remain a daunting challenge for clinicians and researchers alike. While difficult to completely understand, most chronic diseases, including late-onset dementias, are thought to arise as an interplay between host genetic factors and environmental insults. One of the most diverse and ubiquitous environmental insults centers on infectious agents. Associations of infectious agents with late-onset dementia have taken on heightened importance, including our investigations of infection by the intracellular respiratory bacterium, Chlamydia pneumoniae ( $C p n)$, in late-onset dementia of the Alzheimer's type.

Recent Findings Over the last two decades, the relationship of this infection to pathogenesis in late-onset dementia has become much clearer. This clarity has resulted from applying contemporary molecular genetic, biochemical, immunochemical, and cell culture techniques to analysis of human brains, animal models, and relevant in vitro cell culture systems. Data from these studies, taken in aggregate form, now can be applied to evaluation of proof of concept for causation of this infection with late-onset disease. In this evaluation, modifications to the original Koch postulates can be useful for elucidating causation.

Summary All such relevant studies are outlined and summarized in this review, and they demonstrate the utility of applying modified Koch postulates to the etiology of late-onset dementia of the Alzheimer's type. Regardless, it is clear that even with strong observational evidence, in combination with application of modifications of Koch's postulates, we will not be able to conclusively state that $C p n$ infection is causative for disease pathogenesis in late-onset dementia. Moreover, this conclusion obtains as well for the putative causation of this condition by other pathogens, including herpes simplex virus type 1, Borrelia burgdorferi, and Porphyromonas gingivalis.
\end{abstract}

Keywords Chlamydia pneumoniae · Infection · Pathogenesis · Late-onset dementia · Alzheimer's disease

\section{Introduction}

Historically, chronic disease genesis has been difficult to understand, and many diverse mechanisms have been proposed

This article is part of the Topical Collection on Bacteriology

Brian J. Balin

Brianba@pcom.edu

Alan P. Hudson

ahudson@med.wayne.edu

1 Department of Bio-Medical Sciences, Center for Chronic Disorders of Aging, Philadelphia College of Osteopathic Medicine, Evans Hall, 4170 City Avenue, Philadelphia, PA 19131, USA

2 Department of Biochemistry, Immunology, and Microbiology, Wayne State University School of Medicine, Detroit, MI, USA to explain its occurrence. Most chronic diseases currently are thought to result from multifactorial interactions among host genetic factors and a variety of environmental insults [1]. This holds true for late-onset dementia of the Alzheimer's type (referred to as late-onset dementia below for simplicity), and quite possibly for other more generally delineated late-onset dementias. Unlike familial Alzheimer's disease (FAD), lateonset dementia is not a result of specific gene mutations; rath$\mathrm{er}$, it is an interplay between genetic risk factors, such as polymorphisms of the ApoE locus on chromosome 19, and environmental exposure to various influences, including infection [2-6]. Over the past 30 years, numerous reports have linked infectious agents with late-onset dementia [7••]. Various pathogens including viruses, bacteria, fungi, and parasites have been postulated to be associated with different populations of late-onset dementia sufferers. Importantly, critical questions have arisen regarding whether one or more of these 
agents is/are causative in disease genesis, or whether they are merely associated with disease as a result of brain changes obtaining during the process of disease genesis. These questions have led many researchers to evaluate the presence of proposed pathogens in brain tissues and fluids from late-onset dementia patients, most of which had been obtained at autopsy via a variety of technical approaches. The technical approaches to assessing pathogen presence and causation of damage have ranged from molecular genetic analyses to immunohistochemistry to biochemistry to culturing and various forms of ultrastructural analysis. Further, animal modeling studies have attempted to correlate infection with the pathology arising in late-onset dementia. We discuss these and other studies in detail in this review, and we emphasize those studies that focus on the possible role of infection with the obligate intracellular pathogen Chlamydia pneumoniae (Cpn) as an agent of disease genesis.

\section{Implication of the Olfactory System in Brain Infection}

Through detailed study of the brain from late-onset dementia patients, we obtained evidence for the association of specific infections with disease. Evaluation of particular regions of the brain for infection, as well as knowledge of structure-function relationships relevant to entry mechanisms to these regions, is vital to understanding the specificity of brain infection as it affects the onset of disease pathogenesis. The earliest damage in late-onset dementia is seen in the lateral entorhinal cortex, with synaptic changes followed by damage in the hippocampal formation; both of these function to receive olfactory information $[8,9]$. Intriguingly, the "olfactory vector hypothesis" suggests that diseases such as Alzheimer's disease (AD) and Parkinson's disease (PD) may be caused or triggered by agents entering the brain through the nose. This hypothesis is not a new concept and follows from observations that smell loss and olfactory bulb pathology precede by a decade the symptomatic phase of $\mathrm{AD}$ and $\mathrm{PD}$, along with evidence that numerous airborne xenobiotics can enter the brain through the nasal olfactory mucosa [10-13]. A large body of literature provides evidence that infectious agents, metals, herbicides, and prions utilize the olfactory network for access into the brain [14]. These findings do not unequivocally associate any of these agents with specific disease causation, however, and thus, there is a significant need to characterize more extensively infectious involvement of the olfactory network in late-onset dementia. We are not suggesting here that any single agent is responsible solely for non-genetic triggering or causation in late-onset dementia; however, a focus on underlying infections in the olfactory system is of real importance. The importance of infections and other environmental insults with relevance to olfaction is well-reviewed in a recent article on olfactory dysfunction in the pathophysiological continuum of dementia [15]. In this regard, our discovery of Cpn in the late-onset brain is relevant, since this is a ubiquitous intracellular respiratory pathogen which has been shown to infect the olfactory regions of the brain [2]. Cpn has been identified in both human autopsy samples and mouse olfactory bulbs in experimental animal models $[2,16,17,18 \bullet \bullet]$. In animals, the organism appears to spread in a centripetal fashion from the olfactory bulbs into the brain $[16,17,18 \cdot \bullet, 19]$. We do not understand completely the consequences of all of these data, but over the past 20 years, we have uncovered significant characteristics of this infection that may lead to a better global understanding of infectious insult in late-onset dementias in general $[20 \bullet \cdot]$.

Alzheimer's neuropathology has been identified in the olfactory mucosa [21], the olfactory bulbs [22, 23, 24••, 25], the anterior olfactory nucleus $[23,26]$, and deeper structures of the olfactory cortex [27-29]. Some debate exists as to whether pathology first appears in the peripheral olfactory structures or in deeper brain structures prior to olfactory involvement [30-32]. This is in part due to interpretation of the amount or density of pathology found in areas such as the amygdala and hippocampus, as compared to peripheral purely olfactory structures [9]. A xenobiotic using the olfactory pathway for entry to the brain may or may not initiate overt damage to olfactory peripheral cells prior to changes in the primary brain regions receiving input. Interestingly, in patients with mild cognitive impairment, $\beta$-amyloid aggregates have been shown in the olfactory mucosa [21], and sensory deficits including olfaction are detectable in the preclinical phase of lateonset dementia [33]. These observations suggest that peripheral olfactory structures may exhibit early insult prior to deeper brain changes. Taken together, these data may suggest that a relationship exists between the neuropathology in lateonset dementia and infection with $C p n$ in the olfactory network. Further characterization is critical to advancing our knowledge of how infection may trigger and/or exacerbate neuropathogenesis. These and other observations outlined below support the idea that infection by this pathogen is an early event in the initiation of neuropathogenesis, and not a consequence of prior damage providing access for infection of the central nervous system.

\section{Evaluation of $C$. pneumoniae in the Human Brain}

Our initial report described finding DNA of Cpn in 90\% (17/ 19) of postmortem brain samples from patients with late-onset dementia, using specific PCR assays [2], but in only 5\% (1/19) of postmortem, age-matched, non-demented, control brain samples. In 17/19 brains from dementia patients, positive samples were obtained from at least one area with neuropathology (e.g., temporal regions, entorhinal cortex, hippocampus, parietal cortex, pre-frontal cortex), and in four cases, from the cerebellum. In the latter brains, severe neuropathology existed throughout. In the two brains from dementia patients that were 
PCR-negative, only mild pathology was observed, suggesting that a relationship exists between infection and significant pathological changes. Samples from PCR-positive brains also were immuno-positive for $C p n$ antigens in perivascular macrophages, microglia, and astroglia. Immuno-electron microscopy using anti-chlamydial antibodies revealed both the infectious form of Cpn, termed elementary bodies (EB), and the actively metabolizing form termed reticulate bodies $(\mathrm{RB})$ in the PCR and antigen-positive brains [2, 34].

Frozen brain samples revealed intact bacterial mRNA specific to $C p n$, and recovery of viable bacteria was successful from homogenates of 2 brains positive by PCR and RT-PCR; however, it was negative from 2 control brains [2]. These findings suggest that $C p n$ as an intracellular bacterium infected the demented individual at some point during life and not simply by infection at the time of death, since the organism would not have had time to infect cells in the brain tissue. Analysis of the entire olfactory network from control, mild cognitive impairment, and dementia patients could address the correlation of infection to the onset of pathology. This approach would significantly assist in elucidating when infection occurs in relation to pathology and symptom diagnosis. Additional analyses in our original studies revealed that 11 PCR-positive samples had at least one allele for the APOE $\varepsilon 4$ isoform (64\%), consistent with that allele being a risk factor for late-onset dementia [6], as well as a modulator of the Ccomplement response to pathogens. Interestingly, a separate study in individuals with reactive arthritis showed $C p n$ DNA in their synovial tissues; $68 \%$ had at least one copy of the $A P O E \& 4$ allele [3]. These observations implicate a relationship between the APOE\&4 allelic genotype and infection by $C p n$ and that together both factors may confer increased risk for chronic disease genesis [2, 3].

Following our initial studies, other groups attempted identification of Cpn in brain tissue and other samples from patients with late-onset dementia. Those studies provided mixed results, with some reports giving positive identification [35, 36], and others failing to find DNA or antigens, for the most part, in their samples [37-40]; many different techniques were used in these studies, with no other study using identical methodology to our own. Specifically, positive and negative reports utilized PCR and immunohistochemical techniques that differed from one another with regard to protocols and samples examined. Some used formalin-fixed brain samples and others used frozen brain samples for PCR. For immunohistochemistry, different laboratories used different antibodies and dilutions thereof, antigen retrieval or not, and different preparations of sections with regard to fixation and thickness. In fact, one study used impression slides of frozen tissue in their immunohistochemical approach [40]. Knowing full-well of the capriciousness of the techniques used by different laboratories, these varied results are not surprising; our initial study used a variety of molecular, immunohistochemical, ultrastructural, and culturing techniques for these very reasons. In a previous review of other literature in which $\mathrm{Cpn}$ was implicated as a factor in disease genesis, discrepancies in analytical methods among laboratories, and the variable data resulting from them, were pointed out [41].

Acknowledging these discrepancies, we continue to use, and have expanded upon, all techniques used in our initial studies to evaluate human brain tissues for infection. Other independent reports for $\mathrm{Cpn}$ in human cerebrospinal fluid (CSF) [42] and human brain tissues are noted [43, 44]. Interestingly, in one of these studies of atherosclerosis and Cpn involvement in which individuals died at a relatively younger age, little brain pathology was noted [44]. These findings suggest that $\mathrm{Cpn}$ may arise in the brain prior to observable pathological changes. In addition, our replicative studies published in 2006, employing new tissues obtained from brain banks not previously used by us, demonstrated Cpn in relevant brain samples from dementia patients [45]. In our replicative study, PCR analysis targeting two $C p n$ genes revealed PCR positivity in 20/25 late-onset brains, and from $3 / 27$ control brains [45]. The organism was cultured from late-onset brains, and various chlamydial transcripts from those brains demonstrated viability and metabolic activity. Immunohistochemical analyses revealed that astrocytes, microglia, and $\sim 20 \%$ of neurons were infected with $C p n$. The finding of a large proportion of neurons positive for the organism in this study was unique [45]. As in our initial study though, infected cells were located in close proximity to both neuritic senile plaques and neurofibrillary tangle-containing neurons in the brain [2]. In a separate study from 2010 [46], intracellular and extracellular labeling for Cpn was found in the entorhinal cortex, the hippocampus, and the frontal cortex of dementia brains [46]. Serial sections from these areas exhibited both fibrillar amyloid (thioflavin S stained) pathology and Chlamydia immunoreactivity in apposition to one another. Two extracellular patterns of chlamydial immunoreactivity were observed: a punctate pattern and an amorphous foci pattern. These likely represent extrusion of whole organism (punctate) or secreted chlamydial products, e.g., lipopolysaccharide (LPS, amorphous foci) [47, 48]. These observations suggest that $C p n$ has a tropism for olfactory-connected structures such as the entorhinal cortex, amygdala, and hippocampus, brain regions demonstrating the earliest damage in lateonset dementia of the Alzheimer's type [8,9]; infection at these sites may incite inflammation acting as a trigger for amyloid production and deposition. Other factors including other infectious agents may also incite inflammation and pathology in brains and regions in which Cpn is not involved as we readily acknowledge that $\mathrm{Cpn}$ would not be expected to be present in all cases of late-onset dementia.

Cpn has been demonstrated in both human and animal olfactory bulbs $[2,16,17]$; in mice, the organism appeared to spread centripetally from the olfactory bulbs into the 
piriform cortex and to secondary olfactory centers such as the thalamus $[16,17,19]$. Uptake of organisms by the olfactory neuroepithelia also may lead to amyloid peptide generation at this peripheral site and may affect the overall integrity of this region. Others have shown experimentally using intranasal delivery of either polyinosinic:polycytidylic acid (PolyI:C) [49] or LPS [50•] that immune cell infiltration, inflammation, and levels of degeneration are prominent at the entry levels of the olfactory network. In the aged human brain, in which regeneration capacity of the olfactory neuroepithelia has been shown to be compromised [51], infectious and other insults may lead to a more prominent damage response than that seen in younger individuals. Importantly, both olfactory and lung routes for infection of the central nervous system are supported by DNA sequencing studies in which the organism isolated from late-onset brain samples was shown to be more closely related to respiratory than to atherosclerotic strains [52]. Molecular genetic and cell biological characteristics for two isolates of Cpn from late-onset brains were found to be genetically diverse (i.e., not clonal), as with most respiratory isolates [53]. Analyses for single nucleotide polymorphisms (SNPs) indicated several differences from standard respiratory isolates, but no genetic attributes suggested a specific neurotropism [52]. Intriguingly, infection of the olfactory network effectively would allow infection to bypass the blood brain barrier, suggesting that olfactory insult could be the primary pathway by which pathology is initiated in late-onset dementia.

\section{Animal Models of $C$. pneumoniae Infection in the Brain}

Previous models of late-onset dementia of the Alzheimer's type have utilized transgenic mice which overexpress mutants of presenilins, $\beta$-amyloid protein precursor, and tau genes [54]. Overexpression of amyloid results in development of amyloid plaques in the brain, paralleling the pathology observed in FAD. However, these systems do not address the initiating events of late-onset disease, in which mutations in these same genes are not present. As proof of principle for involvement of infection in late-onset dementia, we developed a non-transgenic animal model to address whether infection with a relevant brain isolate of $C p n$ in naïve $\mathrm{BALB} / \mathrm{c}$ mice would promote damage in the animal brain similar to that identified in human late-onset dementia [2]. Since nontransgenic mice do not normally develop relevant neuropathology, they are a suitable host for analyzing whether infection leads to pathological change(s) in their brains. We used $\mathrm{BALB} / \mathrm{c}$ mice, which are susceptible to, and can maintain, a persistent respiratory infection with $C p n$ [55]. We found evidence supporting our contention that infection with the organism can initiate processes resulting in the development of relevant pathology in the brain [16]. In the current iterations of our animal model, we are assessing behavioral changes including learning and memory (Skinner operant chamber) of mice infected with Cpn. Our intent is to determine whether infection induces functional changes which parallel the pathological changes occurring during the progression to dementia. These data will address the contention that $C p n$ can induce both pathology and behavioral changes similar to those observed in late-onset dementia of the Alzheimer's type.

Precedents for infection in the exacerbation of dementiarelated neuropathology have been reported for other pathogens in other animal models $[56,57]$. Once infection has been controlled, levels of soluble amyloid apparently decrease, resulting in fewer deposits at 3-4 months [58]; nevertheless, targeting strategies at and around the time of infection have not been tested and could finally resolve whether Cpn is the triggering factor for the neuropathology. In mice infected with a $C p n$ brain isolate in our studies, $\beta$-amyloid deposits were identified as early as 2 months post-infection, with the greatest number of deposits identified at 3 months [16] causing a progressive Alzheimer-like pathology. Further, models utilizing direct injection of microbial products causing a sterile infection have shown induction of amyloid production and deposition $[59,60]$. However, not all studies have reached the same conclusion, as a prior study by others failed to identify substantial pathology in the brain following infection with a different laboratory strain of Cpn [61]. The authors noted that discrepancies could have resulted from use of the laboratory isolate, which may have had different virulence properties than the human brain isolate.

In our animal model, Cpn was identified in the olfactory epithelia and the olfactory bulbs by both light and electron microscopy following intranasal infection [16]. Analysis of pathology in the brain revealed A $\beta 1-42$ deposits that resembled Alzheimer amyloid plaques. Intranasal infection results in cumulative pathology in the brains of BALB/c mice, and subsequent inoculations result in an additive effect in the degree of pathology. Activation of astrocytes and co-localization of reactive astrocytes with amyloid deposits suggested that a cellular inflammatory response was being initiated. This response may be focused on Cpn alone, or it may be directed against amyloid deposits or to soluble amyloid. These observations suggest that $A \beta$ generation is a response to the infectious insult and lend support to the hypothesis that $A \beta$ can act as a "bioflocculant" [62]. Other studies have suggested that $\mathrm{A} \beta$-amyloid may have antibacterial properties, providing support for its occurrence as a result of infection in the brain [63, 64]. Induction of amyloid deposits in the brains of nontransgenic BALB/c mice further supports our contention that infection with $C p n$ in the brain is causative for the initial Alzheimer-like neuropathology that evolves. This is further corroborated by our earlier study using Moxifloxacin in Cpn-infected mice, where minimal amyloid deposition was observed in infected animals that received antibiotics within 
7-21 days post-infection. In comparison, animals not receiving antibiotics, or those with delayed treatment at 56-70 days post-infection, amyloid plaque numbers were $8-9$-fold higher [65].

Our observations indicate that isolates of Cpn differ in the ability to establish persistent infection and to promote progressive neuropathology. Thus, we have focused on using both a brain isolate (i.e., obtained from late-onset dementia brains) and a laboratory isolate (AR-39) originally obtained from a respiratory infection. Further, a critical issue in development of late-onset dementia is the age of the individual, with greater age demonstrating greater risk for disease. In this regard, the age at which Cpn infection occurs may also influence likelihood of brain infection. With this in mind, an earlier study from our group indicated that Cpn infection of older as compared to younger animals resulted in more prominent establishment of a brain infection that was statistically significant following intranasal inoculation [17]. Also, we inoculated a small group of BALB/c mice with the AR-39 isolate either twice or three times at 30-day intervals, then sacrificed at day 90. Animals inoculated twice displayed an average of $68 \mathrm{am}-$ yloid deposits, and those inoculated 3 times averaged 177 deposits (unpublished observations). Mice receiving only a single intranasal inoculation showed an average of 17-18 deposits at 3 months post-infection, suggesting that multiple inoculations exacerbate damage in the brain. Although we do not know how dosing or multiple exposures to infectious agents through olfaction may affect the human population, our findings may have implications for how the risk of neuropathogenesis may arise following multiple exposures to infecting agents.

In the late-onset brain, inflammation is thought to result from $A \beta$ deposition, which has been advanced as the primary mechanism in late-onset dementia pathogenesis [66]. Clinical trials investigating the effects of non-steroidal anti-inflammatory drugs (NSAIDs) also implicate inflammation as a factor, since some have shown that these drugs can delay onset of disease [67]; however, they appear to be ineffective as a therapeutic once the disease becomes manifest. Interestingly, some untreated immunosuppressed individuals appear to have an increased risk of $\mathrm{AD}$, but with treatment with anti-TNF $\alpha$ agents, the risk for $\mathrm{AD}$ is lowered [68]. At this time, the factors leading to increased risk in the immunosuppressed population are unknown. The resident cells in the brain responsible for inflammation are typically microglia and astroglia. Both are activated in the late-onset brain and often are identified in and around amyloid plaques [69]. Microglia and astroglia respond to insult by producing proinflammatory cytokines and reactive oxygen species (ROS). Our identification of Cpn in the central nervous system (CNS) in microglia, astroglia, perivascular macrophages, and neurons suggested that infection-initiated inflammation could be involved in the early neuropathology of late-onset disease [2, 45]. Contributions also could come from $C p n$-infected monocytes and endothelial cells that we observed in late-onset brains [2, 70]. As proof of concept for our observations, others have shown that proinflammatory molecules are significantly higher in culture supernatant fluids of $C p n$-infected murine microglial cells compared with controls [71]. Further, infected murine astrocytes showed higher levels of MCP-1 and IL-6 compared to controls. Neurons exposed to conditioned supernatant from infected murine microglial cells showed increased cell death compared with mock-infected supernatants. These data may reflect what is occurring following infection in situ.

\section{Culture Studies of $C$. pneumoniae Infection}

Monocytes are known to be involved with the expression of cytokines, apoptosis, and $\beta$-amyloid clearance in $\mathrm{AD}[72-75$, 76.], and our observations indicate that transcription of monocyte genes encoding inflammatory products changes significantly at $48 \mathrm{~h}$ post- $C p n$ infection. Infected cells maintain proinflammatory cytokine secretion over 5 days, including IL$1 \beta$, IL-6, and IL-8 [76 $]$. High levels of IL- $1 \beta$ are correlated with neuroinflammation in the late-onset brain [77-80]. This cytokine activates nitric oxide synthase, which has been implicated in hippocampal neuronal cell death [81, 82]. Other studies have implicated IL- $1 \beta$ in promotion of the neuronal synthesis of the $\beta$-amyloid precursor protein [80]. Such observations provide a rationale for triggering events in which the production of $A \beta$ would be a consequence in late-onset disease.

Interestingly, four genes were upregulated after $48 \mathrm{~h}$ infection in our in vitro studies, each of which encodes a product involved with host defense against bacterial infection [76 $]$. One, $D E F B 4$, encodes a defensin protein with anti-microbial activity linking innate and adaptive immune responses [83]. Another encodes inflammasomes, IPAF and AIM2, which are associated with toll-like receptors and which mediate the response to both extracellular and intracellular pathogens [84]. $N L R C 4$ can be activated by type III secretion systems characteristic of $C p n$ and other gram negative bacteria [85]; this system acts to transfer effector proteins from the bacteria into the cytosol of the host cell, resulting in generation of reactive oxygen species (ROS). ROS are thought to result from the assemblage of another inflammasome complex, NLRP3 [86, 87], which also is activated by chlamydial infections [88, 89]. Upregulation of the AIM2 inflammasome transcript may have been the result of detecting double-stranded DNA from the organism in the cytosol $[90,91]$. The fourth transcript encodes MCP1/CCL2, a key chemokine for recruiting monocytes and macrophages; this was increased 1000 -fold following infection of monocytes with $C p n[76 \bullet, 92]$. This gene product is an important contributor to the neuroinflammatory process observed in late-onset dementia and is increased in both CSF and plasma from individuals with MCI and dementia [93, 
94]. CCL2 may allow increased monocyte migration into brain tissues; it also may affect production and clearance of A $\beta$ from the brain [93-95].

Cell biological studies have demonstrated standard inclusion and chlamydial morphology for both isolates in human epithelial cells (HEp-2), astrocytes (U-87 MG), and microglial cells (CHME-5), as in our previous studies [96]; this is also the case for standard Cpn inclusion morphology in the human microglial cell line HMC3 in our current studies. Chlamydia-induced disease is largely a result of immunopathogenesis. Chlamydial infection promotes secretion of proinflammatory cytokines [97]; strong inflammatory responses are initiated by chlamydial LPS, heat shock proteins, and outer membrane proteins. LPS alone may account for many aspects of late-onset dementia pathology, as studies have shown that Escherichia coli LPS, when injected at low dose into the brains of rats, results in inflammation characterized by increased cytokine production and microglial activation [98]; induction of the $\beta$-amyloid precursor protein also was observed in the rat temporal lobe, suggesting that products of infection alone could stimulate cellular changes resulting in neurodegeneration.

\section{Persistence of C. pneumoniae Infection and Host Responses}

Many studies have shown that under certain conditions and/or within specific host cell types, Cpn alters its biologic state to generate persistent, long-term infections [99-101]. Chlamydiae undergoing such infections are morphologically aberrant and display an unusual transcriptional profile [99-101]. Importantly, the mechanisms of pathogenesis differ between active and persistent chlamydial infection, and it is in the persistent state that these organisms are thought to elicit chronic disease $[102,103]$. Cpn has been associated with several chronic pulmonary diseases [104] and an array of non-respiratory diseases, including atherosclerosis, inflammatory arthritis, multiple sclerosis, and others [105-108]. Studies relevant to late-onset dementia have included analyses of Cpn infection in vitro in both neuronal [109] and astrocyte cell lines [110•0]. In SK-N-MC neuronal cultures at 3 to 10 days post-infection, cells were resistant to apoptosis when induced by staurosporine, suggesting that $C p n$ may induce chronic infection by interfering with apoptosis, a feature found in the late-onset dementia brain, in which apoptosis can be initiated but does not necessarily go to completion [111]. With regard to astrocytes, $\mathrm{Cpn}$ infection in culture promoted transcriptional upregulation of genes involved in neuroinflammation, lipid homeostasis, microtubule function, and amyloid precursor protein processing. Protein levels for the secretases BACE1 and PSEN1 were twofold higher than in controls. BACE1 enzymatic activity was also shown to be increased, suggesting that infected cells promoted a pro-amyloidogenic pathway [110••]. Together with evidence in the late-onset dementia brain of infection in astroglia, microglia, and neurons, a rationale for involvement of $\mathrm{Cpn}$ infection in neuroinflammation and amyloid protein processing and generation of $\beta$-amyloid is compelling.

\section{Proof of Principle of $C$. pneumoniae as a Causative Agent of Late-Onset Dementia}

Traditionally, proofs of infection causing disease have invoked Koch's Postulates, which were a set of rules for which infectious agents were associated with disease causation. Interestingly, Koch himself realized that not all organisms which caused a particular disease fell within the confines of his particular postulates [for review see 112]. In this regard, viruses and obligate intracellular bacteria, which are not freeliving (a condition of one of the four postulates), cannot be cultured without parasitizing another host cell or organism. Thus, proof of concept studies for these types of infectious agents cannot fit easily into Koch's postulates, but rather require a modification or redefinition by which proof of causation should now be accepted. We contend that the postulates derived by Koch should now be addressed in the following manner, given our and others' data.

1. The microorganism must be found in abundance in all organisms suffering from the disease, but should not be found in healthy organisms.

a. We first found Cpn in 17/19 late-onset dementia brains and only $1 / 19$ control brains [2]. In a replicative study, we found Cpn in 20/25 dementia brains and only $3 / 27$ control brains [45].

2. The microorganism must be isolated from a diseased organism and grown in pure culture.

a. Cpn is an obligate intracellular pathogen that requires a host cell for culturing, which cannot be grown in pure culture, however

b. Cpn was isolated from a human brain, cultured in human THP1 monocytes, and subsequently identified by immunohistochemistry, PCR, and electron microscopy [2].

3. The cultured microorganism should cause disease when introduced into a healthy organism.

a. The human brain isolate of $C p n$ that was cultured in THP1 monocytes was purified and inoculated into normal $\mathrm{BALB} / \mathrm{c}$ mice and resulted in $\mathrm{A} \beta$-amyloid accumulation in the mouse brain [16].

4. The microorganism must be re-isolated from the inoculated, diseased experimental host, and identified as being identical to the original.

a. The human brain isolate that created "AD-like" pathology was purified from the infected mouse brain. It 
was clearly identified by immunohistochemistry and PCR from the mouse brain isolate, and

b. Human brain isolates of Cpn were sequenced and resemble human respiratory strains of Cpn $[52,53]$.

\section{Conclusion}

The observations summarized here demonstrating an association of Cpn infection and late-onset dementia of the Alzheimer's type suggest that this infection could be causative for disease pathogenesis if we accept the outlined modifications of Koch's postulates addressed herein. Without demonstration that treatment of late-onset dementia patients for infection can correct the problem, we cannot unequivocally claim that disease is caused by $C p n$ infection or any other infectious agent. Only through initiating clinical trial approaches in which anti-infectives and possibly anti-inflammatory regimens are tested in the late-onset population will we have more definitive answers as to whether infection is a significant cause underlying and eliciting late-onset dementia of the Alzheimer's type.

\section{Compliance with Ethical Standards}

Conflict of Interest The authors declare that they have no conflicts of interest.

Human and Animal Rights and Informed Consent This article does not contain any studies with human or animal subjects performed by any of the authors.

Open Access This article is licensed under a Creative Commons Attribution 4.0 International License, which permits use, sharing, adaptation, distribution and reproduction in any medium or format, as long as you give appropriate credit to the original author(s) and the source, provide a link to the Creative Commons licence, and indicate if changes were made. The images or other third party material in this article are included in the article's Creative Commons licence, unless indicated otherwise in a credit line to the material. If material is not included in the article's Creative Commons licence and your intended use is not permitted by statutory regulation or exceeds the permitted use, you will need to obtain permission directly from the copyright holder. To view a copy of this licence, visit http://creativecommons.org/licenses/by/4.0/.

\section{References}

Papers of particular interest, published recently, have been highlighted as:

- Of importance

-• Of major importance

1. O'Connor SM, Taylor CE, Hughes JM. Emerging infectious determinants of chronic diseases. Emerg Infect Dis. 2006;12(7): $1051-7$.
2. Balin BJ, Gerard HC, Arking EJ, Appelt DM, Branigan PJ, Abrams JT, et al. Identification and localization of Chlamydia pneumoniae in the Alzheimer's brain. Med Microbiol Immunol. 1998;187(1):23-42.

3. Gerard HC, Wang GF, Balin BJ, Schumacher HR, Hudson AP. Frequency of apolipoproteinE (APOE) allele types in patients with Chlamydia-associated arthritis and other arthritides. Microb Pathog. 1999;26(1):35-43.

4. Itzhaki RF, Lin WR, Shang D, Wilcock GK, Faragher B, Jamieson GA. Herpes simplex virus type 1 in brain and risk of Alzheimer's disease. Lancet. 1997;349(9047):241-4.

5. Itzhaki RF, Dobson CB, Lin WR, Wozniak MA. Association of HSV1 and apolipoprotein E-varepsilon4 in Alzheimer's disease. J Neuro-Oncol. 2001;7(6):570-1.

6. Roses AD. Apolipoprotein E alleles as risk factors in Alzheimer's disease. Annu Rev Med. 1996;47:387-400.

7.• Itzhaki RF, Lathe R, Balin BJ, Ball MJ, Bearer EL, Braak H, et al. Microbes and Alzheimer's Disease. J Alzheimers Dis. 2016;51(4): 979-84 This review highlights the important concept of infection related to late-onset Alzheimer's disease. The authors offer critical evaluation for the consideration of infection as a major underlying feature of late-onset disease.

8. Christen-Zaech S, Kraftsik R, Pillevuit O, Kiraly M, Martins R, Khalili K, et al. Early olfactory involvement in Alzheimer's disease. Can J Neurol Sci. 2003;30(1):20-5.

9. Mann DM, Tucker CM, Yates PO. Alzheimer's disease: an olfactory connection? Mech Ageing Dev. 1988;42(1):1-15.

10. Roberts E. Alzheimer's disease may begin in the nose and may be caused by aluminosilicates. Neurobiol Aging. 1986;7(6):561-7.

11. Doty RL, Reyes PF, Gregor T. Presence of both odor identification and detection deficits in Alzheimer's disease. Brain Res Bull. 1987;18(5):597-600.

12. Ferreyra-Moyano H, Barragan E. The olfactory system and Alzheimer's disease. Int J Neurosci. 1989;49(3-4):15-97.

13. Hawkes CH, Shephard BC, Daniel SE. Is Parkinson's disease a primary olfactory disorder? QJM. 1999;92(8):473-80.

14. Doty RL. The olfactory vector hypothesis of neurodegenerative disease: is it viable? Ann Neurol. 2008;63(1):7-15.

15. Bathini P, Brai E, Auber LA. Olfactory dysfunction in the pathophysiological continuum of dementia. Ageing Res Rev. 2019;55: 100956.

16. Little CS, Hammond CJ, MacIntyre A, Balin BJ, Appelt DM. Chlamydia pneumoniae induces Alzheimer-like amyloid plaques in brains of BALB/c mice. Neurobiol Aging. 2004;25(4):419-29.

17. Little CS, Bowe A, Lin R, Litsky J, Fogel RM, Balin BJ, et al. Age alterations in extent and severity of experimental intranasal infection with Chlamydophila pneumoniae in $\mathrm{BALB} / \mathrm{c}$ mice. Infect Immun. 2005;73(3):1723-34.

18.• Little CS, Joyce TA, Hammond CJ, Matta H, Cahn D, Appelt $\mathrm{DM}$, et al. Detection of bacterial antigens and Alzheimer's disease-like pathology in the central nervous system of BALB/c mice following intranasal infection with a laboratory isolate of Chlamydia pneumoniae. Front Aging Neurosci. 2014;5(6):304 Infection with the laboratory strain of $\mathrm{Cpn}$ promotes deposition of amyloid beta, however, this appears to resolve following reduction of the $\mathrm{Cpn}$ antigen burden over time. The data suggest that infection with the AR-39 laboratory isolate of Cpn results in a different course of amyloid beta deposition and ultimate resolution than that observed following infection with the human AD-brain Cpn isolate, 96-41. These data suggest differences, possibly in virulence factors, between Cpn isolates in the generation of sustainable $A D$ pathology.

19. Itzhaki RF, Wozniak MA, Appelt DM, Balin BJ. Infiltration of the brain by pathogens causes Alzheimer's disease. Neurobiol Aging. 2004;25(5):619-27. 
20.• Balin BJ, Hammond CJ, Little CS, Hingley ST, Al-Atrache Z, Appelt DM, Whittum-Hudson JA, Hudson AP (2018). Chlamydia pneumoniae: an etiologic agent for late-onset dementia. In Frontiers in Aging Neuroscience, topic: An Infectious Origin of Alzheimer's Disease: An End for This Devastating Disorder? J Miklossy, R Tanzi, K McCully, G Perry, C Cotman, StJohn Crean, MR Chapman, T Fulop, P McGeer, RDavid Moir, HB Allen (Eds). 10:302. https://doi.org/10.3389/fnagi.2018. 00302. Previously published data and recent results that support involvement of Chlamydia pneumoniae in disease induction and development are reviewed in this manuscript. Several areas for future research are suggested that should elucidate details relating to those processes, and an argument for a change in the designation of the disease based on increased understanding of its clinical attributes was made.

21. Ayala-Grosso CA, Pieruzzini R, Diaz-Solano D, Wittig O, Abrante L, Vargas L, et al. Amyloid-abeta peptide in olfactory mucosa and mesenchymal stromal cells of mild cognitive impairment and Alzheimer's disease patients. Brain Pathol. 2015;25(2): $136-45$.

22. Mundinano IC, Caballero MC, Ordonez C, Hernandez M, DiCaudo C, Marcilla I, et al. Increased dopaminergic cells and protein aggregates in the olfactory bulb of patients with neurodegenerative disorders. Acta Neuropathol. 2011;122(1):61-74.

23. Kovacs I, Torok I, Zombori J, Kasa P. Cholinergic structures and neuropathologic alterations in the olfactory bulb of Alzheimer's disease brain samples. Brain Res. 1998;789(1):167-70.

24.• Bathini P, Mottas A, Jaquet M, Brai E, Alberi L. Progressive signaling changes in the olfactory nerve of patients with Alzheimer's disease. Neurobiol Aging. 2019;76:80-95 This research indicates that the olfactory nerve undergoes early and sequential morphological and signaling alterations that correlates with the development of dementia. These data suggest that this structure may capture and propagate neuronal network imbalances to connected higher brain centers of the entorhinal cortex and hippocampus.

25. Lachen-Montes M, Zelaya MV, Segura V, Fernandez-Irigoyen J, Santamaria E. Progressive modulation of the human olfactory bulb transcriptome during Alzheimer s disease evolution: novel insights into the olfactory signaling across proteinopathies. Oncotarget. 2017;8(41):69663-79.

26. ter Laak HJ, Renkawek K, van Workum FP. The olfactory bulb in Alzheimer disease: a morphologic study of neuron loss, tangles, and senile plaques in relation to olfaction. Alzheimer Dis Assoc Disord. 1994;8(1):38-48.

27. Arriagada PV, Growdon JH, Hedley-Whyte ET, Hyman BT. Neurofibrillary tangles but not senile plaques parallel duration and severity of Alzheimer's disease. Neurology. 1992;42(3 Pt 1): 631-9.

28. Scott SA, DeKosky ST, Sparks DL, Knox CA, Scheff SW. Amygdala cell loss and atrophy in Alzheimer's disease. Ann Neurol. 1992;32(4):555-63.

29. Vereecken TH, Vogels OJ, Nieuwenhuys R. Neuron loss and shrinkage in the amygdala in Alzheimer's disease. Neurobiol Aging. 1994;15(1):45-54.

30. Kovacs T, Cairns NJ, Lantos PL. Olfactory centres in Alzheimer's disease: olfactory bulb is involved in early Braak's stages. Neuroreport. 2001;12(2):285-8.

31. Braak H, Braak E. Demonstration of amyloid deposits and neurofibrillary changes in whole brain sections. Brain Pathol. 1991;1(3): 213-6.

32. Price JL, Davis PB, Morris JC, White DL. The distribution of tangles, plaques and related immunohistochemical markers in healthy aging and Alzheimer's disease. Neurobiol Aging. 1991;12(4):295-312.
33. Sperling RA, Aisen PS, Beckett LA, Bennett DA, Craft S, Fagan AM, et al. Toward defining the preclinical stages of Alzheimer's disease: recommendations from the National Institute on AgingAlzheimer's Association workgroups on diagnostic guidelines for Alzheimer's disease. Alzheimers Dement. 2011;7(3):280-92.

34. Arking EJ, Appelt DM, Abrams JT, Kolbe S, Hudson AP, Balin BJ. Ultrastructural analysis of Chlamydia pneumoniae in the Alzheimer's brain. Pathogenesis. 1999;1(3):201-11.

35. Mahony J, Woulfe J, Munoz D, Chong S, Browning D, Smieja M, Saikku P. Chlamydia pneumoniae in the Alzheimer's brain-Is DNA detection hampered by low copy number. 2000 Proceedings of the 4th Meeting of the European Society for Chlamydia Research editor Pekka Saiku (University of Helsinki). Helsinki Finland.

36. Ossewaarde JM, Gielis-Proper SK, Meijer A, Roholl P. Chlamydia pneumoniae antigens are present in the brains of Alzheimer patients, but not in the brains of patients with other dementias. 2000 Proceedings of the 4th meeting of European Society for Chlamydia Research, editor Pekka Saiku (University of Helsinki). Helsinki Finland.

37. Gieffers J, Reusche E, Solbach W, Maass M. Failure to detect Chlamydia pneumoniae in brain sections of Alzheimer's disease patients. J Clin Microbiol. 2000;38(2):881-2.

38. Nochlin D, Shaw CM, Campbell LA, Kuo CC. Failure to detect Chlamydia pneumoniae in brain tissues of Alzheimer's disease. Neurology. 1999;53(820025176):1888.

39. Ring RH, Lyons JM. Failure to detect Chlamydia pneumoniae in the late-onset Alzheimer's brain. J Clin Microbiol. 2000;38(7): 2591-4.

40. Taylor GS, Vipond IB, Paul ID, Matthews S, Wilcock GK, Caul EO. Failure to correlate $C$. pneumoniae with late onset Alzheimer's disease. Neurology. 2002;59(1):142-3.

41. Campbell LA, Kuo CC. Chlamydia pneumoniae-an infectious risk factor for atherosclerosis? Nat Rev Microbiol. 2004;2(1): 23-32.

42. Paradowski B, Jaremko M, Dobosz T, Leszek J, Noga L. Evaluation of CSF-Chlamydia pneumoniae, CSF-tau, and CSFAbeta42 in Alzheimer's disease and vascular dementia. J Neurol. 2007;254(2):154-9.

43. Rassu M, Cazzavillan S, Scagnelli M, Peron A, Bevilacqua PA, Facco M, et al. Demonstration of Chlamydia pneumoniae in atherosclerotic arteries from various vascular regions. Atherosclerosis. 2001;158(1):73-9.

44. Pietro MD, Filardo S, Cazzavillan S, Segala C, Bevilacqua P, Bonoldi E, et al. Could past chlamydial vascular infection promote the dissemination of Chlamydia pneumoniae to the brain? J Biol Regul Homeost Agents. 2013;27(1):155-64.

45. Gerard HC, Dreses-Werringloer U, Wildt KS, Deka S, Oszust C, Balin BJ 2nd. WHF, Bordayo EZ, Whittum-Hudson JA, Hudson AP. Chlamydophila (Chlamydia) pneumoniae in the Alzheimer's brain. FEMS Immunol Med Microbiol. 2006;48(3):355-66.

46. Hammond CJ, Hallock LR, Howanski RJ, Appelt DM, Little CS, Balin BJ. Immunohistological detection of Chlamydia pneumoniae in the Alzheimer's disease brain. BMC Neurosci. 2010;11:121

47. Stuart ES, Troidle KM, MacDonald AB. Chlamydial glycolipid antigen: extracellular accumulation, biological activity, and antibody recognition. Curr Microbiol. 1994;28(2):85-90.

48. Hybiske K, Stephens RS. Mechanisms of host cell exit by the intracellular bacterium Chlamydia. Proc Natl Acad Sci U S A. 2007;104(27):11430-5.

49. Kanaya K, Kondo K, Suzukawa K, Sakamoto T, Kikuta S, Okada $\mathrm{K}$, et al. Innate immune responses and neuroepithelial degeneration and regeneration in the mouse olfactory mucosa induced by intranasal administration of poly(I:C). Cell Tissue Res. 2014;357(1):279-99. 
50. Hasegawa-Ishii S, Shimada A, Imamura F. Lipopolysaccharideinitiated persistent rhinitis causes gliosis and synaptic loss in the olfactory bulb. Sci Rep. 2017;7(1):1160 LPS administration induced an inflammatory response in the olfactory mucosa that exerted a detrimental effect, not only on olfactory sensory neurons, but also on olfactory bulb neurons, which might lead to neurodegeneration.

51. Child KM, Herrick DB, Schwob JE, Holbrook EH, Jang W. The Neuroregenerative capacity of olfactory stem cells is not limitless: implications for aging. J Neurosci. 2018;38(31):6806-24.

52. Roulis E, Bachmann NL, Myers GS, Huston W, Summersgill J, Hudson A, et al. Comparative genomic analysis of human Chlamydia pneumoniae isolates from respiratory, brain and cardiac tissues. Genomics. 2015;106(6):373-83.

53. Dreses-Werringloer U, Bhuiyan M, Zhao Y, Gerard HC, Whittum-Hudson JA, Hudson AP. Initial characterization of Chlamydophila (Chlamydia) pneumoniae cultured from the lateonset Alzheimer brain. Int J Med Microbiol. 2009;299(3):187201.

54. Guenette SY, Tanzi RE. Progress toward valid transgenic mouse models for Alzheimer's disease. Neurobiol Aging. 1999;20:20111.

55. Laitinen K, Laurila AL, Leinonen M, Saikku P. Reactivation of Chlamydia pneumoniae infection in mice by cortisone treatment. Infect Immun. 1996;64(4):1488-90.

56. McManus RM, Higgins SC, Mills KH, Lynch MA. Respiratory infection promotes $\mathrm{T}$ cell infiltration and amyloid-beta deposition in APP/PS1 mice. Neurobiol Aging. 2014;35(1):109-21.

57. Wang XL, Zeng J, Feng J, Tian YT, Liu YJ, Qiu M, et al. Helicobacter pylori filtrate impairs spatial learning and memory in rats and increases beta-amyloid by enhancing expression of presenilin-2. Front Aging Neurosci. 2014;6:66. https://doi.org/ 10.3389/fnagi.2014.00066 eCollection 2014.

58. Hawkes CA, Deng L, Fenili D, Nitz M, McLaurin J. In vivo uptake of beta-amyloid by non-plaque associated microglia. Curr Alzheimer Res. 2012;9(8):890-901.

59. Krstic D, Madhusudan A, Doehner J, Vogel P, Notter T, Imhof C, et al. Systemic immune challenges trigger and drive Alzheimerlike neuropathology in mice. J Neuroinflammation. 2012;9:151. https://doi.org/10.1186/1742-2094-9-151.

60. Erickson MA, Hartvigson PE, Morofuji Y, Owen JB, Butterfield DA, Banks WA. Lipopolysaccharide impairs amyloid beta efflux from brain: altered vascular sequestration, cerebrospinal fluid reabsorption, peripheral clearance and transporter function at the blood-brain barrier. J Neuroinflammation. 2012;9:150. https:// doi.org/10.1186/1742-2094-9-150.

61. Boelen E, Stassen FR, van der Ven AJ, Lemmens MA, Steinbusch $\mathrm{HP}$, Bruggeman CA, et al. Detection of amyloid beta aggregates in the brain of BALB/c mice after Chlamydia pneumoniae infection. Acta Neuropathol. 2007;114(3):255-61

62. Robinson SR, Bishop GM. Abeta as a bioflocculant: implications for the amyloid hypothesis of Alzheimer's disease. Neurobiol Aging. 2002;23(6):1051-72.

63. Soscia SJ, Kirby JE, Washicosky KJ, Tucker SM, Ingelsson M, Hyman B, et al. The Alzheimer's disease-associated amyloid betaprotein is an antimicrobial peptide. PLoS One. 2010;5(3):e9505.

64. Kumar DK, Choi SH, Washicosky KJ, Eimer WA, Tucker S, Ghofrani J, et al. Amyloid-beta peptide protects against microbial infection in mouse and worm models of Alzheimer's disease. Sci Transl Med. 2016;8(340):340ra72.

65. Hammond CJ, Little CS, Longo N, Procacci C, Appelt DM, Balin BJ. Antibiotic alters inflammation in the mouse brain during persistent Chlamydia pneumoniae infection. Alzheimers Dis New Adv. 2006:295-9.

66. Lue LF, Brachova L, Civin WH, Rogers J. Inflammation, Abeta deposition, and neurofibrillary tangle formation as correlates of
Alzheimer's disease neurodegeneration. J Neuropathol Exp Neurol. 1996;55(10):1083-8.

67. Breitner JC. The role of anti-inflammatory drugs in the prevention and treatment of Alzheimer's disease. Annu Rev Med. 1996;47: 401-11.

68. Chou RC, Kane M, Ghimire S, Gautam S, Gui J. Treatment for rheumatoid arthritis and risk of Alzheimer's disease: a nested casecontrol analysis. CNS Drugs. 2016;30(11):1111-20.

69. Wood PL. Roles of CNS macrophages in neurodegeneration. Neuroinflammation: Springer; 1998. p. 1-59.

70. MacIntyre A, Abramov R, Hammond CJ, Hudson AP, Arking EJ, Little CS, et al. Chlamydia pneumoniae infection promotes the transmigration of monocytes through human brain endothelial cells. J Neurosci Res. 2003;71(5):740-50.

71. Boelen E, Steinbusch HW, van der Ven AJ, Grauls G, Bruggeman CA, Stassen FR. Chlamydia pneumoniae infection of brain cells: an in vitro study. Neurobiol Aging. 2007;28(4):524-32.

72. Fiala M, Lin J, Ringman J, Kermani-Arab V, Tsao G, Patel A, et al. Ineffective phagocytosis of amyloid-beta by macrophages of Alzheimer's disease patients. J Alzheimers Dis. 2005;7(3):22-62.

73. Fiala M, Cribbs DH, Rosenthal M, Bernard G. Phagocytosis of amyloid-beta and inflammation: two faces of innate immunity in Alzheimer's disease. J Alzheimers Dis. 2007;11(4):457-63.

74. Saresella M, Marventano I, Calabrese E, Piancone F, Rainone V, Gatti A, et al. A complex proinflammatory role for peripheral monocytes in Alzheimer's disease. J Alzheimers Dis. 2014;38(2):403-13.

75. Feng Y, Li L, Sun XH. Monocytes and Alzheimer's disease. Neurosci Bull. 2011;27(2):115-22.

76. Lim C, Hammond CJ, Hingley ST, Balin BJ. Chlamydia pneumoniae infection of monocytes in vitro stimulates innate and adaptive immune responses relevant to those in Alzheimer's disease. J Neuroinflammation. 2014;11:217. https://doi.org/10. 1186/s12974-014-0217-0 The results of this study demonstrate that Cpn infection of THP1 human monocytes promotes an innate immune response and suggests a potential role in the initiation of inflammation in sporadic/late-onset Alzheimer's disease.

77. Sheng JG, Ito K, Skinner RD, Mrak RE, Rovnaghi CR, Eldik $\mathrm{LJV}$, et al. In vivo and in vitro evidence supporting a role for the inflammatory cytokine interleukin-1 as a driving force in Alzheimer pathogenesis. Neurobiol Aging. 1996;17(5):761-6.

78. Mrak RE, Griffin WS. Interleukin-1, neuroinflammation, and Alzheimer's disease. Neurobiol Aging. 2001;22(6):903-8.

79. Serou MJ, DeCoster MA, Bazan NG. Interleukin-1 beta activates expression of cyclooxygenase-2 and inducible nitric oxide synthase in primary hippocampal neuronal culture: plateletactivating factor as a preferential mediator of cyclooxygenase-2 expression. J Neurosci Res. 1999;58(4):593-8.

80. Griffin WS, Sheng JG, Gentleman SM, Graham DI, Mrak RE, Roberts GW. Microglial interleukin-1 alpha expression in human head injury: correlations with neuronal and neuritic beta-amyloid precursor protein expression. Neurosci Lett. 1994;176(2):133-6.

81. Blum-Degen D, Muller T, Kuhn W, Gerlach M, Przuntek H, Riederer P. Interleukin-1 beta and interleukin- 6 are elevated in the cerebrospinal fluid of Alzheimer's and de novo Parkinson's disease patients. Neurosci Lett. 1995;202(1-2):17-20.

82. Cacabelos R, Barquero M, Garcia P, Alvarez XA. Seijas EVd. Cerebrospinal fluid interleukin-1 beta (IL-1 beta) in Alzheimer's disease and neurological disorders. Methods Find Exp Clin Pharmacol. 1991;13(7):455-8.

83. Hollox EJ, Armour JA, Barber JC. Extensive normal copy number variation of a beta-defensin antimicrobial-gene cluster. Am J Hum Genet. 2003;73(3):591-600.

84. Schroder K, Tschopp J. The inflammasomes. Cell. 2010;140(6): 821-32. 
85. Miao EA, Warren SE. Innate immune detection of bacterial virulence factors via the NLRC4 inflammasome. J Clin Immunol. 2010;30(4):502-6.

86. Abdul-Sater AA, Koo E, Hacker G, Ojcius DM. Inflammasomedependent caspase-1 activation in cervical epithelial cells stimulates growth of the intracellular pathogen Chlamydia trachomatis. J Biol Chem. 2009;284(39):26789-96.

87. Abdul-Sater AA, Said-Sadier N, Ojcius DM, Yilmaz O, Kelly KA. Inflammasomes bridge signaling between pathogen identification and the immune response. Drugs Today (Barc). 2009;45(Suppl B):105-12.

88. He X, Mekasha S, Mavrogiorgos N, Fitzgerald KA, Lien E, Ingalls RR. Inflammation and fibrosis during Chlamydia pneumoniae infection is regulated by IL-1 and the NLRP3/ASC inflammasome. J Immunol. 2010;184(10):5743-54.

89. Abdul-Sater AA, Said-Sadier N, Padilla EV, Ojcius DM. Chlamydial infection of monocytes stimulates IL-1beta secretion through activation of the NLRP3 inflammasome. Microbes Infect. 2010;12(8-9):652-61.

90. Fernandes-Alnemri T, Yu JW, Datta P, Wu J, Alnemri ES. AIM2 activates the inflammasome and cell death in response to cytoplasmic DNA. Nature. 2009;458(7237):509-13.

91. Hornung V, Ablasser A, Charrel-Dennis M, Bauernfeind F, Horvath G, Caffrey DR, et al. AIM2 recognizes cytosolic dsDNA and forms a caspase-1-activating inflammasome with ASC. Nature. 2009;458(7237):514-8.

92. Ubogu EE, Cossoy MB, Ransohoff RM. The expression and function of chemokines involved in CNS inflammation. Trends Pharmacol Sci. 2006;27(1):48-55.

93. Galimberti D, Schoonenboom N, Scheltens P, Fenoglio C, Venturelli E, Pijnenburg YA, et al. Intrathecal chemokine levels in Alzheimer disease and frontotemporal lobar degeneration. Neurology. 2006;66(1):146-7.

94. Fiala M, Zhang L, Gan X, Sherry B, Taub D, Graves MC, et al. Amyloid-beta induces chemokine secretion and monocyte migration across a human blood-brain barrier model. Mol Med. 1998;4(7):480-9.

95. Yamamoto M, Horiba M, Buescher JL, Huang D, Gendelman HE, Ransohoff RM, et al. Overexpression of monocyte chemotactic protein-1/CCL2 in beta-amyloid precursor protein transgenic mice show accelerated diffuse beta-amyloid deposition. Am J Pathol. 2005;166(5):1475-85

96. Dreses-Werringloer U, Gerard HC, Whittum-Hudson JA, Hudson AP. Chlamydophila (Chlamydia) pneumoniae infection of human astrocytes and microglia in culture displays an active, rather than a persistent, phenotype. Am J Med Sci. 2006;332(4):168-74.

97. Rasmussen SJ, Eckmann L, Quayle AJ, Shen L, Zhang YX, Anderson DJ, et al. Secretion of proinflammatory cytokines by epithelial cells in response to Chlamydia infection suggests a central role for epithelial cells in chlamydial pathogenesis. J Clin Invest. 1997;99(1):77-87.

98. Hauss-Wegrzyniak B, Lukovic L, Bigaud M, Stoeckel ME. Brain inflammatory response induced by intracerebroventricular infusion of lipopolysaccharide: an immunohistochemical study. Brain Res. 1998;794(2):211-24.

99. Byrne GI, Ouellette SP, Wang Z, Rao JP, Lu L, Beatty WL, et al. Chlamydia pneumoniae expresses genes required for DNA replication but not cytokinesis during persistent infection of HEp-2 cells. Infect Immun. 2001;69(9):5423-9.

100. Gerard HC, Krausse-Opatz B, Wang Z, Rudy D, Rao JP, Zeidler $\mathrm{H}$, et al. Expression of Chlamydia trachomatis genes encoding products required for DNA synthesis and cell division during active versus persistent infection. Mol Microbiol. 2001;41(3):73141.

101. Gerard HC, Whittum-Hudson JA, Schumacher HR, Hudson AP. Differential expression of three Chlamydia trachomatis hsp60encoding genes in active vs. persistent infections. Microb Pathog. 2004;36(1):35-9.

102. Hogan RJ, Mathews SA, Mukhopadhyay S, Summersgill JT, Timms P. Chlamydial persistence: beyond the biphasic paradigm. Infect Immun. 2004;72(4):1843-55.

103. Whittum-Hudson JA, Schumacher HR, Hudson AP. Chlamydia pneumoniae and inflammatory arthritis. In: Yamamoto Y, Friedman H, Bendinelli M, editors. Chlamydia pneumoniae Infection and Diseases. New York: Kluwer/Academic Press. p. 227-38.

104. Clementsen P, Permin H, Norn S. Chlamydia pneumoniae infection and its role in asthma and chronic obstructive pulmonary disease. J Investig Allergol Clin Immunol. 2002;12(2):7-9.

105. Schumacher HR Jr, Arayssi T, Crane M, Lee J, Gerard H, Hudson $\mathrm{AP}$, et al. Chlamydia trachomatis nucleic acids can be found in the synovium of some asymptomatic subjects. Arthritis Rheum. 1999;42(6):1281-4.

106. Wagner AD, Gerard HC, Fresemann T, Schmidt WA, GromnicaIhle E, Hudson AP, et al. Detection of Chlamydia pneumoniae in giant cell vasculitis and correlation with the topographic arrangement of tissue-infiltrating dendritic cells. Arthritis Rheum. 2000;43(7):1543-51.

107. Belland RJ, Ouellette SP, Gieffers J, Byrne GI. Chlamydia pneumoniae and atherosclerosis. Cell Microbiol. 2004;6(2):11727.

108. Sriram S, Mitchell W, Stratton C. Multiple sclerosis associated with Chlamydia pneumoniae infection of the CNS. Neurology. 1998;50(298145402):571-2.

109. Appelt DM, Roupas MR, Way DS, Bell MG, Albert EV, Hammond CJ, et al. Inhibition of apoptosis in neuronal cells infected with Chlamydophila (Chlamydia) pneumoniae. BMC Neurosci. 2008 Jan 24;9:13.

110.• Al-Atrache Z, Lopez DB, Hingley ST, Appelt DM. Astrocytes infected with Chlamydia pneumoniae demonstrate altered expression and activity of secretases involved in the generation of betaamyloid found in Alzheimer disease. BMC Neurosci. 2019;20(1): 5 This manuscript demonstrates how Chlamydia pneumoniae infection of human astrocytes promotes the proamyloidogenic pathway of APP processing through the upregulation of expression and activity of $\beta$-secretase, upregulated expression of $\gamma$-secretase, and decreased activity of $\alpha$ secretase. These effects of astrocyte infection provide evidence for a direct link between Chlamydia pneumoniae and AD pathology.

111. Raina AK, Zhu X, Shimohama S, Perry G, Smith MA. Tipping the apoptotic balance in Alzheimer's disease: the abortosis concept. Cell Biochem Biophys. 2003;39(3):249-55.

112. Fredricks DN, Relman DA. Sequence-based identification of microbial pathogens: a reconsideration of Koch's postulates. Clin Microbiol Rev. 1996;9(1):18-33.

Publisher's Note Springer Nature remains neutral with regard to jurisdictional claims in published maps and institutional affiliations. 